\title{
Analysis of Thermal Field in Mineral Transformer Oil Based Magnetic Fluids
}

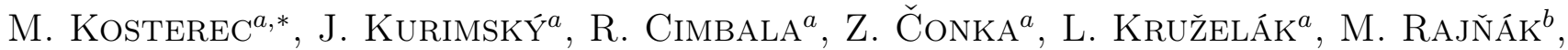 \\ M. TIMKO ${ }^{b}$, P. KOPČANSKÝ ${ }^{b}$ AND B. VARGOVÁ ${ }^{c}$ \\ ${ }^{a}$ Department of Electrical Power Engineering, Technical University of Košice, \\ Faculty of Electrical Engineering and Informatics, Mäsiarska 74, 04120 Košice, Slovakia \\ ${ }^{b}$ Institute of Experimental Physics, SAS, Watsonova 47, 04001 Košice, Slovakia \\ ${ }^{c}$ Institute of Parasitology SAS, Hlinkova 3, 04001 Košice, Slovakia
}

\begin{abstract}
Growing interest in the use of magnetic fluids in power systems especially in transformers as insulation and a coolant is nowadays registered. Magnetisable nanofluids, which are used in cooling systems as an alternative to mineral transformer oil, are characterized by lower concentration of magnetic nanoparticles. The magnetic fluid has better heat transfer and dielectric properties such as breakdown than mineral transformer oil and it can be used to improve heat flow, thereby increasing the ability of the active parts to resist failures such as electromagnetic pulses. External magnetic field may be used for forced circulation of magnetic fluid. Magnetic force inside the magnetic fluid can be adequately controlled by adjusting the incident magnetic field. This paper presents thermal distribution, fluid flow and cooling ability of mineral transformer oil and magnetic fluid based on mineral transformer oil. The concentration of $\mathrm{Fe}_{3} \mathrm{O}_{4}$ magnetic nanoparticles is $0.15 \%$ volume of mineral transformer oil. The thermal field is generated by a steel conductor. Thermal distributions in mineral transformer oil and magnetic fluid are investigated and differences for both cases are discussed in the paper.
\end{abstract}

DOI: 10.12693/APhysPolA.131.937

PACS/topics: 44.25.+f, 44.27.+g, 47.11.Fg, 47.65. Cb

\section{Introduction}

Magnetic fluids are colloidal suspensions of nanosized magnetic particles dispersed in an appropriate carrier fluid. The magnetic fluid has magnetic properties of magnetic nanoparticles and fluidity of carrier fluid $[1,2]$. Magnetic fluids are characterized by higher heat transfer and the ability to use external magnetic field to create forced circulation [3-5].

The temperature dependence of the saturation magnetization and the presence of magnetic field are the basis for a thermomagnetic convection of magnetic fluid. The temperature gradient in fluid will lead to spatial difference in the magnetization due to the temperature dependence of nanoparticles' magnetization which leads to fluid movement [6].

For further details, such as the spectrum of the local electric field, fluid flow and heat transfer in the response to the change of the incident magnetic field can be sometimes obtained only by using numerical simulations $[5,7]$.

Considering that not many papers which deal with the thermal distribution and fluid flow of magnetic fluid were published we present the design of numerical model for evaluating thermal field and fluid flow in cooling fluid. Cooling of heating wire spiral is by natural convection or by thermomagnetic convection. Results from numerical simulation confirm well with experimental measurement.

*corresponding author; e-mail: michal.kosterec@tuke.sk

\section{Materials and methods}

Transformer oil Mogul is used for experimental measurement. Magnetic fluid consists of transformer oil Mogul and $\mathrm{Fe}_{3} \mathrm{O}_{4}$ magnetic nanoparticles whose concentration is $0.15 \%$ volume of transformer oil. Magnetic fluid was prepared according to [8].

Transformer oil or magnetic fluid were placed in cylindrical container $75 \times 70 \mathrm{~mm}^{2}$. Fluid samples were heated up using heating wire spiral with 8 turns and crosssection of $0.75 \mathrm{~mm}^{2}$. The heating wire spiral was powered by DC current of $7 \mathrm{~A}$ (applied magnetic field is $1.7 \mathrm{mT}$ ). Temperature was measured by two thermal sensors placed in the container, one above the heating wire spiral, second near the container wall (Fig. 1). Measurement lasted until fluid reached $100^{\circ} \mathrm{C}$ at temperature sensor 1.

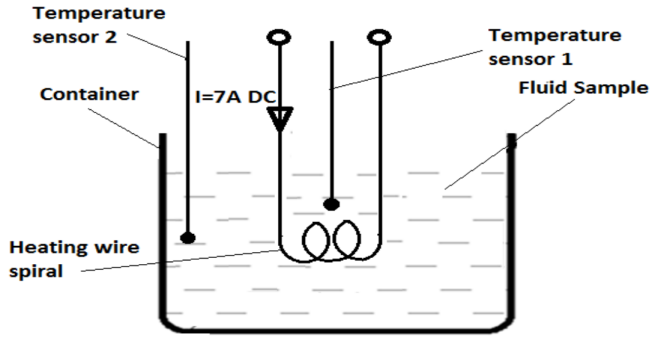

Fig. 1. Experimental setup.

The thermal distribution and fluid flow were obtained using ANSYS Workbench software. Pressure- 
based solver was used with the Boussinesq model which computes buoyancy forces in transformer oil. This model treats density as a constant value in all solved equations, except for the buoyancy term in the momentum equation

$$
\left(\rho-\rho_{0}\right) g \approx-\rho_{0} \beta\left(T-T_{0}\right) g,
$$

where $\rho_{0}$ is the density of the flow, $T_{0}$ is the operating temperature and $\beta$ is the thermal expansion coefficient. Equation (1) is obtained by using the Boussinesq approximation $\rho=\rho_{0}(1-\beta \Delta T)$ to eliminate $\rho$ from the buoyancy term.

Magneto-hydrodynamic model was used for obtaining results for magnetic fluid. The equation for fluid velocity field $\boldsymbol{v}$ in magnetic field $\boldsymbol{B}$ is

$$
\boldsymbol{j}=\sigma(\boldsymbol{E}+\boldsymbol{v} \times \boldsymbol{B})
$$

where $\boldsymbol{j}$ is the current density, $\boldsymbol{E}$ is electric field and $\sigma$ is conductivity.

The properties of transformer oil and magnetic fluid are in Table I $[9,10]$.

Properties of transformer oil and magnetic fluid.

\begin{tabular}{|c|c|c|c|c|c|}
\hline Sample & 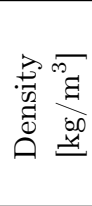 & 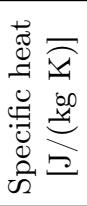 & 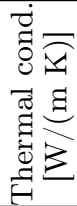 & 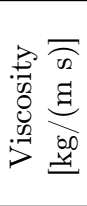 & 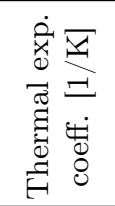 \\
\hline transformer oil & 866 & 1750 & 0.31 & 0.014 & 0.00075 \\
\hline magnetic fluid & 930 & 1850 & 0.59 & 0.023 & 0.00075 \\
\hline
\end{tabular}

TABLE I

\section{Results and discussion}

In both cases the magnetic forces act perpendicularly to buoyant forces. Figure 2 shows rise in temperature of transformer oil during time period obtained from simulation and experimental measurement. From graph it can be seen that temperature difference between two temperature sensors is rising with time and reaches up to $30^{\circ} \mathrm{C}$ at time $1600 \mathrm{~s}$. The transformer oil reaches temperature of $100^{\circ} \mathrm{C}$ at time 1565 s. Figures 3 and 4 show thermal distribution and fluid flow of transformer oil calculated by model. It can be seen that natural convection occurred in transformer oil.

The time dependence of magnetic fluid is shown in Fig. 5 obtained from simulation and experimental measurement. The temperature difference between two temperature sensors is $7^{\circ} \mathrm{C}$ at time $1600 \mathrm{~s}$. Figures 6 and 7 show thermal distribution and fluid flow of magnetic fluid calculated by numerical model. The magnetic fluid reaches temperature of $100^{\circ} \mathrm{C}$ at time $1705 \mathrm{~s}$. Thermomagnetic convection and natural convection occurred in magnetic fluid. The fluid with higher temperature above spiral has a lower magnetic permeability due to temperature dependence of magnetization. It is pushed out towards wall of container by natural convection where it sweeps cold wall and releases heat to the ambient with temperature $24^{\circ} \mathrm{C}$ and cools down. The magnetic permeability of cooled down magnetic fluid rises and magnetic fluid is subsequently driven to the hot spiral by magnetic field and thus creating forced circulation in magnetic fluid (Fig. 7).

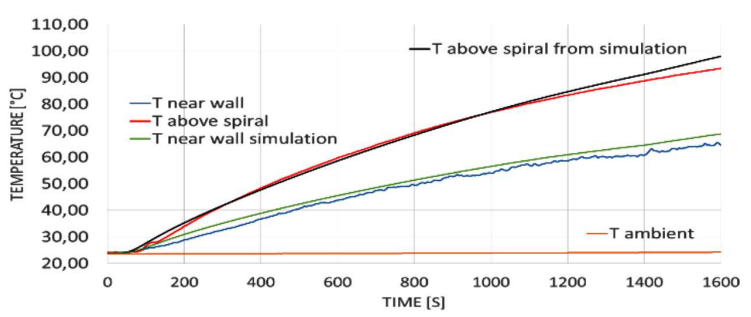

Fig. 2. Temperature of transformer oil during time period of $1600 \mathrm{~s}$ obtained from experiment and simulation.

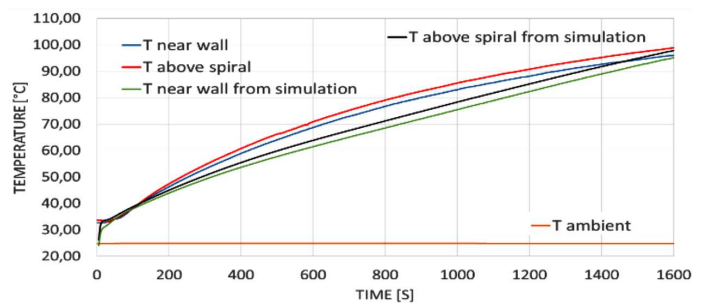

Fig. 3. Temperature of magnetic fluid during time period of $1600 \mathrm{~s}$ obtained from experiment and simulation.

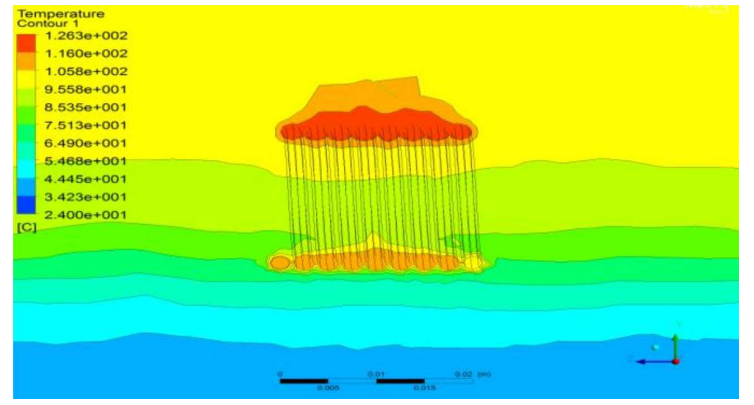

Fig. 4. Thermal distribution in transformer oil at time $1500 \mathrm{~s}$.

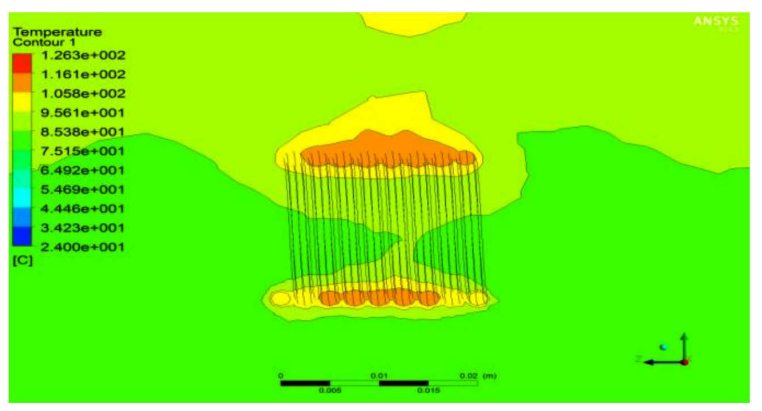

Fig. 5. Thermal distribution in magnetic fluid at time $1500 \mathrm{~s}$. 


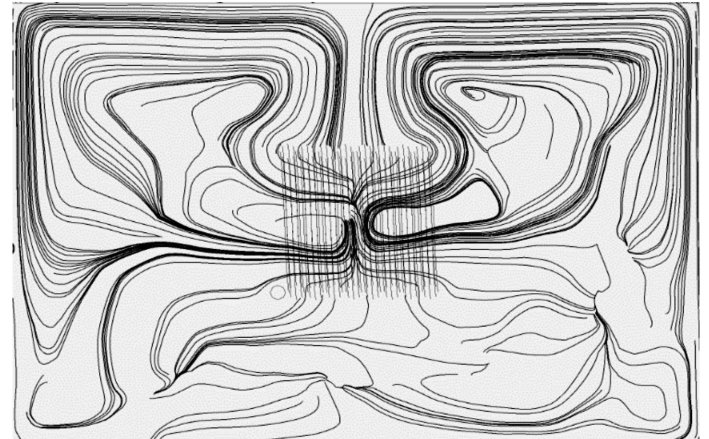

Fig. 6. Streamline of fluid flow in transformer oil at time $1500 \mathrm{~s}$.

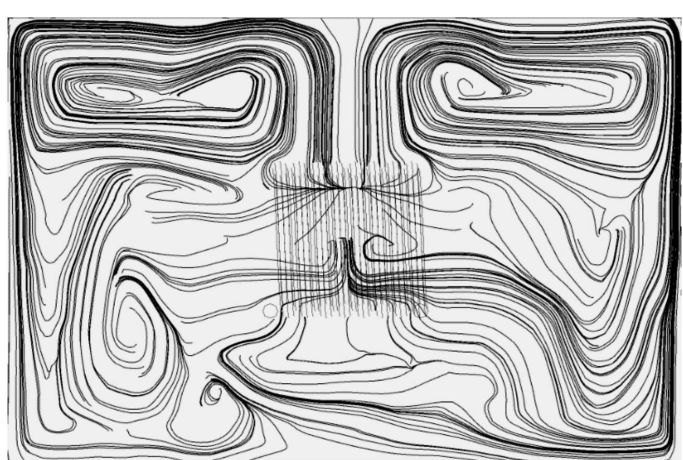

Fig. 7. Streamlines of fluid flow in magnetic fluid at time $1500 \mathrm{~s}$.

The magnetic fluid with lower temperature at the bottom of the container is driven in to the center of spiral where it extracts and dissipates the heat generated in spiral (Fig. 7). The temperature difference in volume of magnetic fluid is not as much as in transformer oil.

The temperature difference between simulation and experimental measurement is maximum $4{ }^{\circ} \mathrm{C}$ for transformer oil and $8^{\circ} \mathrm{C}$ for magnetic fluid (Fig. 2, Fig. 5).

From simulation results the heating wire spiral reaches temperature $100^{\circ} \mathrm{C}$ in transformer oil at time $765 \mathrm{~s}$, while in magnetic fluid it is at time $1107 \mathrm{~s}$. The heat flux from container to ambient using magnetic fluid was $481.15 \mathrm{~W} / \mathrm{m}^{2}$ average while using transformer oil it was $351.25 \mathrm{~W} / \mathrm{m}^{2}$ average. The difference is $129.9 \mathrm{~W} / \mathrm{m}^{2}$ which confirms that magnetic fluid has better cooling ability than transformer oil $[3,4,7]$.

\section{Conclusion}

The experimental and numerical models conducted were aimed to investigate thermal field and fluid flow in transformer oil and magnetic fluid. The numerical model calculated fluid flow and thermal field and it shows the same trends as obtained from measurement even though small inaccuracies were present.
Comparing the results it can be seen that magnetic fluid has better cooling ability than transformer oil. Cooling using magnetic fluid can be useful for cases where convectional convection fails to provide adequate heat transfer or for cooling electromagnetic machinery in limited space. The fluid flow can be driven by using external magnetic field.

\section{Acknowledgments}

This work was supported by: Slovak Academy of Sciences and Ministry of Education in the framework of Projects VEGA No. 1/0132/15, 1/0311/15, and 2/0141/16; Ministry of Education Agency for structural funds of EU in frame of Projects No. 26220120003, 6220120046, and 26220120055; Slovak Research and Development Agency project No. APVV-15-0438., and FEI No. FEI-2015-28.

\section{References}

[1] R.-Q. Lv, Y. Zhao, H. Li, H.-F. Hu, IEEE Trans. Magn. 51, 1 (2015).

[2] G. Thirupathi R. Singh, IEEE Trans. Magn. 51, 1 (2015).

[3] L. Pislaru-Danescu, A.M. Morega, M. Morega, V. Stoica, O.M. Marinica, F. Nouras, N. Paduraru, I. Borbath, T. Borbath, IEEE Trans. Ind. Appl. 49, 1289 (2013).

[4] S. Chaudhari, S. Patil, R. Zambare, S. Chakraborty, 2012 IEEE 10th Int. Conf. on the Properties and Applications of Dielectric Materials (ICPADM), IEEE, 2012, p. 1.

[5] J.G. Hwang, M. Zahn, F.M. O'Sullivan, L.A. Pettersson, O. Hjortstam, R. Liu, J. Appl. Phys. 107, 14310 (2010).

[6] T. Völker, E. Blums, S. Odenbach, GAMM-Mitt. 30, 185 (2007).

[7] A.M. Morega, M. Morega, L. Pîslaru-Dănescu, V. Stoica, F. Nouraş, F.D. Stoian, in: 2010 12th Int. Conf. on Optimization of Electrical and Electronic Equipment (OPTIM), 5510425, IEEE, Brašov 2010, p. 140.

[8] M. Rajnak, J. Kurimsky, B. Dolnik, K. Marton, L. Tomco, A. Taculescu, L. Vekas, J. Kovac, I. Vavra, J. Tothova, P. Kopcansky, M. Timko, J. Appl. Phys. 114, 034313 (2013).

[9] M. Yang, R. O'Handley, Z. Fang, Proc. COMSOL Conf. 2010, Boston 2010, p. 1.

[10] W. Cherief, M. Wu, Y. Avenas, S. Ferrouillat, L. Jossic, A. Lebouc, J. Berard, M. Petit, in: 2014 20th Int. Workshop on Thermal Investigations of ICs and Systems (THERMINIC), 6972499, IEEE, London 2014. 